\title{
Co-pyrolysis Characteristic and Parameters Optimization of Low Rank Coal and Eichhornia Crassipes
}

\author{
Chunxia Wang ${ }^{1, a}$ \\ 1 Huadian Electric Power Research Institute, NO.387 Linjiang Road, \\ Wuchang District, Wuhan 430060, PR China \\ aemail: wangchunxia0409@163.com,
}

\begin{abstract}
Keywords: Co-pyrolysis; Low rank coal; Biomass; Orthogonal experiment; Tar Abstract. Orthogonal experiments were carried out in a fixed reactor to investigate the optimum operation conditions of co-pyrolysis of Hongying coal (HC) and eichhornia crassipes (EC) with the index of tar. The results showed when biomass ratio was $35 \%$, final temperature was at $550{ }^{\circ} \mathrm{C}$, particle size was $0.355-0.500 \mathrm{~mm}$ and stay time was $25 \mathrm{~min}$, the content of alkanes and $\mathrm{H} / \mathrm{C}$ ratio of co-pyrolysis tar were significant increased compared that of tar from coal pyrolysis alone.
\end{abstract}

\section{Introduction}

Coal, especially low rank coal is the most abundant fossil energy resource of the word. However, the traditional coal utilization not only cause the emission of harmful gases, which will worsen air pollution and global warming[1], but also waste the finite nature resource. Thus more and more studies focus on improving the utilization efficiency of coal and looking for cleaner energy alternativesto reduce coal consumption [2].

Biomass is the most promising alternative energy resource. On the one hand, it is the third largest energy[3] and renewable, widespread in the word. On the other hand, biomass is carbon neutral during thermal conversion process. Algae, forestry waste, industrial waste and agricultural residues are the commonly available biomass materials[4,5]. But the potential energy in those biomass hasn't been realized and full used by human. Most biomass resource are decomposed naturally[6]. Biomass and coal have different physical structures and chemical properties such as $\mathrm{H} / \mathrm{C}$ ration, ash and volatile content, moisture, volatile matter and calorific value. If add biomass to the coal conversion process, there will be various effects. The synergistic interactions or inhibition interactions between coal and biomass may affect their thermal reactivity and the properties of three-phase products[4].

The aim of present work is to explore the most optimum experiment conditions for the co-pyrolysis of coal and biomass through orthogonal experiments.

\section{Experiment}

\section{Raw materials}

Eichhornia crassipes sample was collected from the Yangtze River in Wuhan section. The sample was dried in a air dry oven at $40{ }^{\circ} \mathrm{C}$ for $4 \mathrm{~h}$ after being washed. The particles crushed by a shatter machine was selected by standard sieves with $0.045 \mathrm{~mm}, 0.200 \mathrm{~mm}, 0.355 \mathrm{~mm}, 0.500 \mathrm{~mm}$ aperture respectively. Low rank coal used in this study was from Hongying (HC). The preparation of low rank coal was consistent with GB 474-2008, its particle size was less than $0.200 \mathrm{~mm}$. EC and HC were air dry base samples. Table1 shows some characteristics of raw materials 
Table 1 Ultimate and proximate analysis of samples $(w / \%)$

\begin{tabular}{|c|c|c|c|c|c|c|c|c|c|c|}
\hline \multirow{2}{*}{ Samples } & \multicolumn{5}{|c|}{ Ultimate analysis (ad) } & \multirow{2}{*}{$\mathrm{H} / \mathrm{C}$} & \multicolumn{4}{|c|}{ Proximate analysis (ad) } \\
\hline & $\mathrm{C}$ & $\mathrm{H}$ & O* & $\mathrm{N}$ & $S$ & & $\mathrm{M}$ & $\mathrm{A}$ & $\mathrm{V}$ & $\mathrm{FC}$ \\
\hline $\mathrm{HC}$ & 78.02 & 3.97 & 6.80 & 1.10 & 0.83 & 0.61 & 3.24 & 6.23 & 29.31 & 61.22 \\
\hline $\mathrm{EC}$ & 38.11 & 3.78 & 35.18 & 3.07 & 0.72 & 1.19 & 8.32 & 8.67 & 61.57 & 21.44 \\
\hline
\end{tabular}

*By difference

Orthogonal experimental design.

In this paper, the yield of pyrolysis tar was the main evaluation index. L9 (34) orthogonal table was used to study the influence of biomass ration(A), particle size(B), final temperature(C) and stay time(D) on the co-pyrolysis of low-rank coal(HC) and eichhornia crassipes (EC). These four factors are shown in Table 2. It was random to make the experimental order during the trials to make sure there was no subjective bias. Each run was repeated for three times.

Table 2 Factors levels of orthogonal test

\begin{tabular}{lllll}
\hline & Factors & & & \\
\cline { 2 - 5 } Levels & Biomass ratio & Particle size & Final temperature & Stay time \\
& $\mathrm{A} / \%$ & $\mathrm{~B} / \mathrm{mm}$ & $\mathrm{C} /{ }^{\circ} \mathrm{C}$ & $\mathrm{D} / \mathrm{min}$ \\
\hline 1 & 25 & $0.355-0.500$ & 450 & 20 \\
2 & 30 & $0.200-0.355$ & 510 & 25 \\
3 & 35 & $0.045-0.200$ & 550 & 30 \\
\hline
\end{tabular}

\section{GC-MS analysis during the pyrolysis}

The components of pyrolysis tar were analyzed with HP6890A GC-5973MSD gas chromatography- mass spectrometry. Chromatographic conditions: HP190915-433 capillary column, $\mathrm{He}$ as carrier gas, flow rate $1.0 \mathrm{ml} / \mathrm{min}$, split ratio is $20: 1$. Temperature program: inlet temperature 300 ${ }^{\circ} \mathrm{C}$, maintain initial temperature of $40^{\circ} \mathrm{C}$ for $10 \mathrm{~min}$, raise temperature to $280^{\circ} \mathrm{C}$ and keep for $10 \mathrm{~min}$. Mass spectrometry conditions: electron impact ionization source (EI), ionization voltage $70 \mathrm{eV}$, ion source temperature $230^{\circ} \mathrm{C}$, ionization current $250 \mu \mathrm{A}$. To define compounds by mass chromatogram of characteristic ion, spectral, chromatographic retention time and mass data of NIST library on line. 


\section{Results and discussion}

Results of orthogonal experiments for carbonization.

Table 3 Results of orthogonal test

\begin{tabular}{llllll}
\hline \multirow{2}{*}{ Test } & \multicolumn{2}{l}{ Factors } & & & \multirow{2}{*}{ Yield of tar $/ \%$} \\
\cline { 2 - 5 } & $\mathrm{A}$ & $\mathrm{B}$ & $\mathrm{C}$ & $\mathrm{D}$ & \\
\hline 1 & 1 & 1 & 1 & 1 & 10.00 \\
2 & 1 & 2 & 2 & 2 & 10.72 \\
3 & 1 & 3 & 3 & 3 & 10.26 \\
4 & 2 & 1 & 2 & 3 & 11.36 \\
5 & 2 & 2 & 3 & 1 & 10.20 \\
6 & 2 & 3 & 1 & 2 & 8.84 \\
7 & 3 & 1 & 3 & 2 & 11.70 \\
8 & 3 & 2 & 1 & 3 & 10.94 \\
9 & 3 & 3 & 2 & 1 & \\
\hline K1 & 30.98 & 33.06 & 29.78 & 31.54 & \\
K2 & 30.40 & 31.86 & 33.42 & 31.26 & \\
K3 & 33.98 & 30.44 & 32.16 & 32.56 & \\
k1 & 10.33 & 11.02 & 9.93 & 10.51 & \\
k2 & 10.13 & 10.62 & 11.14 & 10.42 & \\
k3 & 11.33 & 10.15 & 10.72 & 10.85 & \\
R & 1.19 & 0.87 & 1.21 & 0.43 & \\
\hline Order & $\mathrm{C}>\mathrm{A}>\mathrm{B}>\mathrm{D}$ & & & \\
Excellent level & $\mathrm{A} 3 \mathrm{~B} 1 \mathrm{C} 2 \mathrm{D} 3$ & & & \\
Excellent combination & $\mathrm{C} 2 \mathrm{~A} 3 \mathrm{~B} 1 \mathrm{D} 3$ &
\end{tabular}

The arrangement of orthogonal experiment and the range analysis are shown in Table 3 . It can be seen from the result of range analysis the primary and secondary relationships of factors was $\mathrm{C}>\mathrm{A}>\mathrm{B}>\mathrm{D}$ within the range of the selected factors level. The most influential factor was the final temperature, followed by ratio and particle size. The influence of stay time was the smallest. Thus the test conditions of $7 \#$ test is the most optimal conditions: the percentage of $\mathrm{EC}$ was $35 \%$, the particle was $0.355-0.500 \mathrm{~mm}$, the final temperature was $550{ }^{\circ} \mathrm{C}$ and the stay time was $25 \mathrm{~min}$. Under these conditions, the pyrolysis tar had the maximum yield $11.70 \%$ shown in the Fig.1.

The primary and secondary reactions of pyrolysis for materials were related to the mechanism of heat transfer and mass transfer. The primary reactions produced main products and intermediates. The intermediates might react secondary cracking reactions divided into homogeneous and heterogeneous reactions including cracking, partial oxidation, reunion and condensation processes[7]. The secondary reactions and carbonization reactions of the pyrolysis tar could be regulated by controlling final temperature and optimize the generation of pyrolysis tar by this[8]. As the pyrolysis temperature increased, the yield of pyrolysis tar production increased at first and then decreased. Because most compositions of the materials had not been decomposed when the temperature was low and there was not so much violate. The final temperature of orthogonal test $1 \#$, $6 \#$ and $8 \#$ were $450{ }^{\circ} \mathrm{C}$. Their tar yield was lower than that of other test at the same ratios. Since some unstable components in the violates might suffer secondary cracking under high temperature on some degree when the temperature was higher than a certain threshold. Then the yield of tar would decrease by being decomposed into non-condensable gases. Thus in order to get more tar, there existed an optimum temperature range which is usually around $500 \sim 600^{\circ} \mathrm{C}$.

\section{Co-pyrolysis experiments of $\mathrm{HC}$ and $\mathrm{EC}$}

The co-pyrolysis experiments of HC and EC were carried out under the optimal experiment conditions worked out by orthogonal experiment. The distribution of pyrolysis products is shown in Fig.1. 


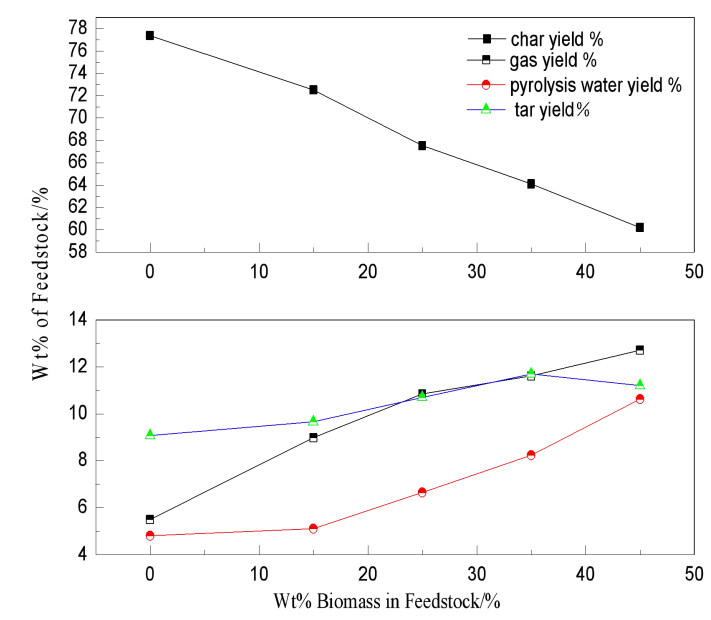

Fig.1. Yield changes of low-temperature co-pyrolysis products

It can be seen from Fig. 1., char has the biggest yield and water has the smallest yield among pyrolysis products. With biomass ratio increasing, the yields of gas and water were increasing and the yield of char was decreasing. It is agreed with the researches of Supachita Krerkkaiwan [10] and Ligang Wei[9]The yield of tar increased at first and then emerged a decreasing trend. The yield of tar had the maximum value $11.70 \%$ at biomass and coal ratio $35: 65$ increased by $29.0 \%$ compered to origin tar. This result was consistent with the discussion about biomass ratio in orthogonal experiments. The yield of char declined was due to less fixed carbon and ash in biomass compared to coal shown in Table 1. The yield of gas rose was also due to the higher content of violate in biomass. Since the oxygen content of biomass was about six times as that of coal and the $\mathrm{H} \cdot$ generated by pyrolysis of samples was easy to combine with $\mathrm{O}$ to form $\mathrm{H}_{2} \mathrm{O}$. Thus the yield of water declined with the biomass ratio increasing. Nonlinear changes of pyrolysis product yields indicated interactions existed in the co-pyrolysis process of biomass and coal[4].

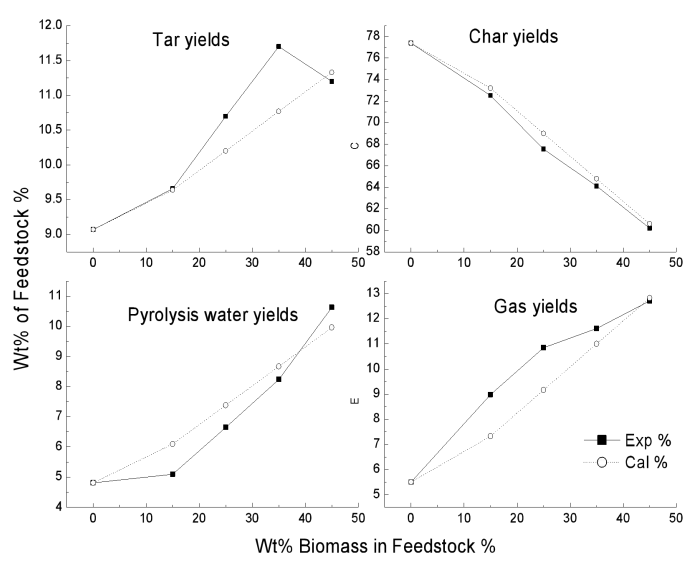

Fig.2. Experiment values and calculated values of product yields from pyrolysis of HC and EC for varying feed blend ratios

Fig.2. shows the products yields of experiments deviate their predicated values significantly. The deviation reached maximum value with $35 \%$ (wt $\%$ ) biomass. Due to higher $\mathrm{H} / \mathrm{C}$ and $\mathrm{O} / \mathrm{C}$ ratios of biomass, plenty of $\mathrm{OH}$ and $\mathrm{H}$ generated could play the role of Hydrogen donors which might promote the aromatic compounds of coal to been formed[2,11]. And it would suppress series of secondary reactions including cross-linking reaction, repolymerization and condensation. Then the formation of secondary char would be reduced[10,12,13]. It can be seen the most remarkable synergetic effect occurred at the biomass content of 35\%. While the yield of tar was lower than its calculated value when biomass content was close to $45 \%$. The promote effect became week and even abrogated with biomass content increasing. It was may be explained by the excess volatiles[14]. 
Large number carbon black produced by advance pyrolysis of biomass would cover the surface of coal and clog the pores which might affect the transfer of heat and escape and spread of violate. Nathan et al[15]suggested the pyrolysis of coal would be influenced by the pyrolysis gas atmosphere $\mathrm{CO} 、 \mathrm{CO} 2 、 \mathrm{CH} 4 、 \mathrm{H} 2 、 \mathrm{H} 2 \mathrm{O}$ from biomass decomposed prior to coal. And the reaction mechanism, conversion and products distribution would be changed if these gases react with coal.

In addition, the presence of synergetic effect in the co-pyrolysis of $\mathrm{HC}$ and $\mathrm{EC}$ might due to the catalysis effect of alkali and alkaline earth metals in the ash of biomass. They had been proved to promote the secondary char to be decomposed and gasified[14,16,17]. Thus except gas-coal reaction ,there might be char-coal reaction during the co-pyrolysis of biomass and coal. Kajitani [18]indicated during the co-pyrolysis of cedar bark and coal , the $\mathrm{K}$ violated from cedar bark improved the reactivity of coal char by condensing over its surface. It indicated that co-pyrolysis of $\mathrm{HC}$ and EC promoted the solid product to be decomposed into volatile products. The experiment yields of pyrolysis water were smaller than their calculated values when ratio of EC was below 35\% and opposite above $35 \%$. Less pyrolysis water was in favor of reducing cost of dehydration for tar and improving the calorific value of tar. So the subsequent experiments selected $30 \%$ as biomass ratio was reasonable.

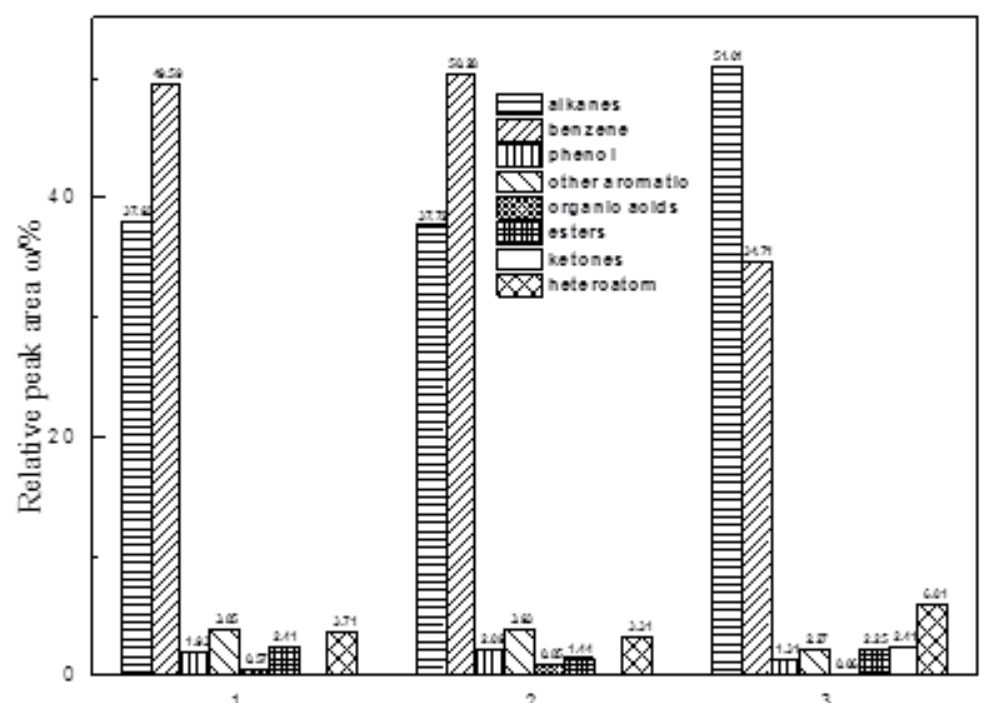

Fig. 3. Contents of organics in different ${ }^{3}$ oils

Detected by GC-MS, Fig. 3. shows the main organics in pyrolysis tar of HC, EC and blend were alkanes, benzene, phenol, other aromatic, organic acids, esters, ketones and heteroatom containing compounds etc. It can be seen the content of alkanes was only $37.93 \%$ in the tar of HC, while it was $51.00 \%$ in the tar of blend, increased significantly compared to $\mathrm{HC}$ pyrolysis alone. It was beneficial for coal to substitute oil and suggested the co-pyrolysis tar became lighter on some degree. Besides, the existence of organic acids not only rusted equipments but also affected the stability of bio-oil by reacting with alcohol. There was $0.85 \%$ organic acids in the tar of EC, $0.57 \%$ in the tar of $\mathrm{HC}$ but only $0.06 \%$ in the tar of blend. Thus co-pyrolysis might avoid corrosion of equipments on some degree and improved the stability of pyrolysis tar. Furthermore, a variety of aromatic and heterocyclic compounds in pyrolysis tar were valuable chemical raw materials.

Table 4 Ultimate analysis and heat value of tar and char

\begin{tabular}{ccccccccc}
\hline \multicolumn{2}{c}{ Samples } & $\mathrm{C}$ & $\mathrm{H}$ & $\mathrm{O}$ & $\mathrm{N}$ & $\mathrm{S}$ & $\mathrm{H} / \mathrm{C}$ & Heat value/MJ•kg-1 \\
\hline \multirow{4}{*}{ Tar } & $\mathrm{HC}$ & 83.89 & 10.44 & 4.29 & 0.92 & 0.46 & 1.49 & 38.28 \\
& EC & 71.10 & 10.06 & 12.16 & 6.31 & 0.37 & 1.70 & 33.48 \\
& Blends & 79.41 & 10.72 & 6.18 & 3.26 & 0.43 & 1.62 & 36.96 \\
\multirow{4}{*}{ Char } & HC & 82.77 & 2.36 & 4.17 & 1.18 & 0.38 & 0.34 & 31.98 \\
& EC & 42.45 & 1.28 & 8.48 & 2.95 & 0.54 & 0.36 & 15.83 \\
& Blends & 75.84 & 2.52 & 6.74 & 1.52 & 0.57 & 0.40 & 30.02 \\
\hline
\end{tabular}


Table 4 shows the elemental analysis of tar and char. It can be seen the $\mathrm{H} / \mathrm{C}$ ratio of tar was much higher than that of char, which indicated $\mathrm{H}$ has been enriched in the tar after low temperature pyrolysis. The $\mathrm{H} / \mathrm{C}$ ratio of co-pyrolysis tar was increased by $8.72 \%$ compared to that of $\mathrm{HC}$ pyrolysis alone, suggesting the adjunction of EC was benefit to light of pyrolysis tar. Besides, the calorific value of char from EC was only $15.83 \mathrm{MJ} / \mathrm{kg}$. While the calorific value of char from blend was about two times as it, which made up for the deficiencies that the calorific value of char from HC pyrolyis alone was too low.

\section{Conclusions}

In this study, the primary and secondary relationships of factors for orthogonal experiments was : final temperature $>$ ratio $>$ particle size $>$ stay time. Under the conditions of biomass ratiowas $35 \%$, final temperature was $550^{\circ} \mathrm{C}$, particle size was $0.355-0.500 \mathrm{~mm}$ and stay time was $25 \mathrm{~min}$, the maximum yield of pyrolysis tar was $11.7 \%$ increased by $29.0 \%$ compared to that of HY pyrolysis alone and rised by $8.6 \%$ than its calculated value.

GC-MS detection results showed the content of alkanes in pyrolysis tar of blend was increased by $34.46 \%$ compared to that of $\mathrm{HC}$ pyrolysis alone. The content of organic acids was also almost declines to zero. It is beneficial for coal to substitute oil and improve the stability of tar. The $\mathrm{H} / \mathrm{C}$ ratio of co-pyrolysis tar was increased by $8.72 \%$ compared to the tar of $\mathrm{HC}$ at the same conditions and its calorific value was $36.96 \mathrm{MJ} / \mathrm{kg}$ slightly lower than that of diesel and gasoline. Thus the yield of pyrolysis tar can be increased without declining its quality under the operation conditions of this study. Decomposition of EC could provide heat for the co-pyrolysis of HC and EC and promoted HC to be decomposed into liquid and gas products at lower temperature.

\section{Reference}

[1] Sonobe T, Worasuwannarak N, Pipatmanomai S: Fuel Processing Technology. Vol. 89(2008), p. 1371.

[2] L Zhang, S Xu, W Zhao and S Liu: Fuel. Vol. 86(2007), p. 353.

[3] Werther J, Saengera M and Hartgea E.-U: Prog Energy Combust Sci. Vol. 26(2000), p.2.

[4] Haykiri-Acma H andYaman S. Ren Energy. Vol. 35(2010), p. 289.

[5] Vassilev SV, Baxter D and Andersen LK: Fuel. Vol. 89(2010), p. 914.

[6] Wihersaari M: Biomass Bioenergy. Vol. 28(2005), p. 446.

[7] Blasi CD: Progress in Energy and Combustion Science. Vol. 34(2008), p. 80.

[8] Akhtar J and Amin NS: Renewable and Sustainable Energy Reviews. Vol. 16(2012), p.5107.

[9] LG Wei, L Zhang and SP Xu: J Fuel Chem Technol.Vol. 39(2011), p. 730.

[10] Park DK, Kim SD, Lee SH and Lee JG: Bioresource Technology. Vol. 101(2010), p.6155.

[11] S Yuan, ZH Dai, ZJ Zhou, XL Chen, GS Yu and FC.Wang: Bioresource Technology. Vol. 109(2012), p.194.

[12] Moghtaderi B, Meesri C and Wall TF: Fuel. Vol. 83(2004), p.747.

[13] Ulloa CA, Gordon AL and Garcia XA: Fuel Processing Technology. 2009; 90:583-90.

[14] Howaniec N, Smolinski A, Stanczyk K and Pichlak M: International Journal of Hydrogen Energy. Vol. 36(2011), p.14459.

[15] Weiland NT, Means NC and Morreale BD: Fuel. Vol. 94(2012), p.568.

[16] WK Zhu, WL Song and WG Lin:Fuel Processing Technology. Vol. 89(2008), p.892.

[17] Kajitani S, Zhang Y, Umemoto S, Ashizawa M and Hara S: Energy Fuel. Vol. 24(2010), p.148.

[18] Wannapeera J, Fungtammasan B and Worasuwannarak N: Journal of Analytical and Applied Pyrolysis. Vol. 92(2011), p.103. 